\title{
Review of Government Performance Management in the Big Data Era: Practice, Issues and Prospects
}

\author{
Wu Zhenqi* \\ School of Government Management, Beijing Normal University, Haidian, Beijing, China
${ }^{*}$ ysuwzq@163.com
}

\begin{abstract}
The development of digital governance in the era of big data provides opportunities for government performance management, promotes the rise and development of government performance management in the data era, and also attracts more and more attention from scholars. This paper systematically combs the literature on government performance from two major aspects: practical exploration and research topics. The study found that big data provides data, technology, and thinking changes for government performance management, and further explores the progress of practice and problems in the operation process. In the future, we need to better classify the micro-factors that affect the application of data in government performance management. At the same time, we must introduce a public value perspective to balance technical rationality and value rationality.
\end{abstract}

Keywords: big data, government performance, practical exploration, controversy

\section{INTRODUCTION}

As a product of informatization and digital technology, big data is profoundly affecting all aspects of economic growth, social development, and government governance. In particular, the large-scale popularization and promotion of big data analysis technology and applications have had a significant impact on government management. At the same time, the use of big data to promote government management changes has quickly become the focus of attention of governments and society in various countries. Many countries and regions have formulated strategies. Among them, the U.S. government took the lead in publishing the "Big Data Research and Development Plan" in 2012, and the governments of the United Kingdom, France, and Japan issued their respective "Data Development Plans and Strategies" and integrated digital technologies. It is widely used in government management to improve internal government management, public service provision, policy formulation, and citizen participation. The advent of the era of big data, as well as the continuous exploration and thinking of innovative practices of big data around the world, have also caused my country's strategic response. In recent years, the government has also actively promoted digital China strategy, government data open sharing project, big data strategy and artificial intelligence development strategy.
Government performance is the result and effectiveness of government management. The pursuit of high-quality performance is not only the fundamental mission of the modern government, but also the basis for improving government efficiency and public satisfaction, promoting the implementation of responsibilities and administrative reforms. . How to continuously improve public performance and better meet the public's demand for public services? The advent of the era of big data has expanded the ideas and methods for solving this issue. In order to better understand the development of government performance management in the era of big data, this article systematically sorts out the relevant research and topics of government performance management in the field of digital governance in recent years on the basis of a brief introduction to relevant foreign practical cases, with a view to future research Make relevant suggestions.

\section{RESEARCH FOCUS: TWO STRATEGIES FOR "DATA" LINKING}

Since the 21 st century, people have begun to enter the era of big data, where information technology and social economy converge. Big data is not only a state of massive data or a series of advanced information technologies, but also a kind of thinking [1]. The essence of data-driven is information-driven [2]. At present, data permeates all 
aspects of society, not only has become a national basic strategic resource, but also the first productive factor and the first governance factor that drives economic and social development [3]. In the field of public governance, big data has also triggered new changes in the way of public governance, and has been applied in the field of public security and public services. Big data analysis technology makes government reform and innovation face certain opportunities and challenges.Big data thinking and technology embedded in government governance activities can more accurately identify problems, make more scientific decisions, and promote government management to the road of accurate, intelligent and intelligent change. However, the public sector is facing governance challenges in big data collection, processing, analysis, interpretation and decision-making. This is because government departments and civil servants are lack of information technology ability compared with enterprises, and it is difficult to make full use of big data analysis technology for governance innovation.In the field of government performance management, big data has also triggered new changes in performance management. By sorting out the operating conditions of different stages of performance management, including performance goals, performance execution, process monitoring, performance communication, performance appraisal, performance auditing, etc., we use massive amounts of diverse data reflecting performance in different forms to analyze the relationship between the data Relationship [4], and then use performance information for problem diagnosis, decision support, organizational learning, performance improvement and other purposes. How the public sector uses Internet technology to effectively apply big data functions to the performance management process will undoubtedly affect the efficiency and effectiveness of the performance management of the public sector substantially.

\section{PRACTICAL EXPLORATION OF GOVERNMENT PERFORMANCE IN DIGITAL GOVERNANCE}

Data analysis or "big data" will fundamentally change society. Although there are many definitions of big data, the vision of a new digital oriented big data practice of collecting, mining, storing and processing data in a new way has been established, and is closely related to the vision of the subsequent transformation of public services and social governance. The practice related to big data, especially around data acquisition, data analysis and scientific decision-making, is changing the practice of government performance management.

\subsection{Application effectiveness}

In terms of big data applications, surveillance practices in Australia, New Zealand, the United Kingdom, and the United States are probably the best known. In 2012, the United States launched the "Big Data Research and Development Program" . In terms of public services, big data is being used to regulate access to social services and welfare; to make decisions on trial strategies, judgments, public order, rehabilitation and child welfare, and to enhance government transparency, accountability and supervision around its use [5]. In the UK, the government has identified big data as one of the "eight major technologies", applying public sector big data to government digital services, work and pensions, and the Ministry of Education, the Ministry of Justice and the Ministry of Home Affairs are investigating data analysis. The Australian government launched a big data strategy in 2013, aiming to become a world leader in the use of big data analysis in the public sector. The government has established a complete center of excellence for government data analysis to develop and build data analysis applications for various government departments in order to improve data management, personalized services, improve problem-solving and decision-making capabilities, and increase productivity and efficiency [6]. Singapore, as one of the earliest use of cloud computing analysis, focuses on the use of big data applications in governance and policy. Through the reorganization of technical institutions, with integrated strategy and implementation, building a smart country platform to drive cloud applications [7].

\subsection{There are problems}

As the government increasingly uses big data systems, it also faces many risks. In terms of technical possibilities, the main challenge is not only technical, but also how to establish a governance structure and involve people in the process of decision-making performance management. The main obstacle that affects the government's adoption of big data is the organization-level restrictions - that is, restrictions around collaboration, resources, and skills [8], especially when dealing with information islands [9]. This isolated method of data management has many data management consequences. In addition, performance information is not used properly, and there is a lack of coordination between big data management and information management in practice [10].

\section{GOVERNMENT PERFORMANCE MANAGEMENT IN THE DATA AGE: DISPUTES AND EXPANSION}

\subsection{Development disputes}

As public organizations invest more and more in big data solutions and applications, people are increasingly aware of the power of data. Government performance management in the era of big data is significantly different from traditional performance management in the collection, analysis and use of performance 
information. Some literature confirms that the application of big data to government performance management not only "public institutions using big data have achieved significantly more positive results and benefits" [11], but also fundamentally changes the government performance management system. In terms of budget performance management, big data technology can improve the quality of budget performance management from four paths: the scientific nature of budget performance target review, the accuracy of performance evaluation, the online real-time monitoring of performance operation, and the visualization of performance information [12].Performance evaluation of big data thinking and technology can improve the objectivity, integrity, timeliness and accuracy of performance information, promote the transition of performance information production from top-down model verification to bottomup fact driven logic, and promote government performance management and evaluation from static evaluation to dynamic evaluation, from lag evaluation to real-time evaluation Comprehensive change from fuzzy evaluation to accurate evaluation. Big data does have more significant data advantages than small data, but the development of big data technology and its application in the public sector is still not mature. Its application in data collection, mining and analysis is still faced with various constraints such as incomplete data, unavailable data and single data. The road to accurate performance information based on big data technology defects is long and difficult. However, for a long time, the performance information output of government performance evaluation activities has faced the dilemma of distortion. In addition, Simon Vydraa,b and Bram Klievink believe that too much emphasis is placed on technical rationality at the expense of political decision-making brought by data, and the relationship between the two should be balanced [13]. At the same time, closely related to it is the issue of ethical use[14].

\subsection{Vision expansion}

With the gradual deepening of research, the latest research results of government performance have shown the characteristics of multiple perspectives. The theory of public value shifts the focus of public sector management from within the organizational boundary to the society from how to better produce public services to how to provide better public services to meet the needs of consumers. The spread of digital technology promotes this transformation and creates a strong argument for public value creation as the ultimate goal of digital government initiatives.Wang Xuejun emphasizes the transition from management to governance, and believes that government performance governance in the digital government era should focus on micro-mechanisms, especially from the perspective of public value creation and collaborative governance, to study the value system formation process and organizational reconstruction process of government performance production under new governance forms [15]. Kroll constructed a modified model to explain the behavior of government performance information, and tried to explain the mechanism of performance information use behavior with variables such as attitude toward performance information, social norms, use intention, and data availability [16]. Some scholars have also introduced social cognition, impression management and information processing theories to explain the use of performance information.

\section{CONCLUSION}

With the advent of the era of big data, data technology application analysis can make the government more responsible to citizens, and even change the traditional governance model. It can be said that big data has the potential to improve the mutual understanding between the government and citizens, and create a new public management model for the digital age. Government performance management is at the crossroads of traditional mode, new mode and new mode. Although big data analysis technology has unlimited potential and is widely used in various fields of government management and public service. However, the application of big data analysis technology in the field of government performance management is far from enough, and there are few related researches, which is in sharp contrast with its rapid development in other fields. There is no doubt that the emergence of big data and the progress of technology and analysis tools provide an opportunity for the emergency performance management framework that intends to use these data, but the real application of big data analysis technology in government performance management is rare. At the same time, few studies examine how big data analysis technology enables government performance management. The reason why the field of government performance management has not been strongly impacted by big data analysis technology is that government performance management itself has strong political sensitivity and has a stake in the interests of various government departments and their staff.

Research shows that compared with the traditional government performance management mode in the era of big data, the government performance management mode in the era of big data has significant differences in many aspects, such as management objectives, data sources, data types, data analysis, management cycle, information use, etc. However, we must also realize that big data is a double-edged sword, which is full of opportunities and challenges on the road of promoting government governance reform. Future research can start from the organization and external environment, focus on the motivation and ability of the public sector, and reveal the key driving factors of big data application. On this 
basis, the key constraints of performance management of big data application in different public sectors are proposed by classification, so as to provide driving force for big data application and remove obstacles. In addition, while big data is embedded in government performance management, the connotation of public value is injected into all aspects of performance management, and the citizen demand confirmation mechanism, performance quality improvement mechanism,performance application and improvement mechanism are gradually explored to balance technical rationality and value rationality.

\section{REFERENCES}

[1] Huang Qisong, Qiu Longyun, Feng Yuanyuan. (2020)The elements and structure driven by big data: a theoretical model [J]. E-government, (04): 49-57.

[2] Meyer-Schoenberger V, Kukje K. (2013)The era of big data: great changes in life, work and thinking $[\mathrm{M}]$. Sheng Yangyan, Zhou Tao, translation. Hangzhou: Zhejiang People's Publishing Hous, The Zhejiang.

[3] Jiang Xiaojuan. (2018)Government management and services in the era of big data: improving capabilities and coping with challenges $[\mathrm{J}]$. Chinese Administration, (9): 6-11.

[4] Tian Wuxing, Wang Haifeng. (2017)The innovation of public sector performance management model in the era of big data- - Enlightenment and reference based on the comparison of KPI and OKR[J]. Economic System Reform, (03): 17-23.

[5] Eubanks V.(2018)Automating Inequality. Macmillan, New York.

[6] Gamage P .(2016)New development: Leveraging 'big data' analytics in the public sector. Public Money \&Management .36(5): 385 - 390.

[7] Ng R . (2018)Cloud Computing in Singapore: Key Drivers and Recommendations for a Smart Nation[J]. Politics and Governance, 6:39-47.

[8] Allard, S., Wiegand, E., Schlecht, C., Datta, R., Goerge, R. and Weigensberg, E.(2018) State Agencies, Use of Administrative Data for Improved Practice: Needs, Challenges, and Opportunities. Public Administration Review .78(2): 240-250.

[9] Zhan Y, Tan K H . (2018)An Analytic Infrastructure for Harvesting Big Data to Enhance Supply Chain Performance[J]. European Journal of Operational Research, 559-574.
[10] Munteanu I , Newcomer K . (2020)Leading and Learning through Dynamic Performance Management in Government[J]. Public Administration Review, (4):316-325.

[11] Maciejewski, M. (2016)To do more, better, faster and more cheaply: Using big data in public administration. International Review of Administrative Sciences,83(1):120 - 135.

[12] Li Wenbin, Xie Xin. (2020)Research on Big Data Technology and Quality Improvement of Budget Performance Management[J]. Study Forum, (04): 38-45.

[13] Vydra S , Klievink B . (2019)Techno-optimism and policy-pessimism in the public sector big data debate[J]. Government Information Quarterly, 36(4):1-10.

[14] Hondula, D., Kuras, E., Longo, J. and Johnston, E. (2018) Toward precision governance: infusing data into public management of environmental hazards. Public Management Review ,5: 746-765.

[15] Wang Xuejun. (2020)Governance transformation of my country's government performance management [J]. Theoretical Exploration, 6: 5-13.

[16] Kroll A.(2015)Explaining the use of performance in- formation by public managers: A plannedbehavior approach [J]. The American Review of Public Administra tion,45(2):201-215. 